\title{
Sociometric Attractiveness on Facebook*
}

\author{
Kate M. Stam ${ }^{1}$, Glen T. Cameron², Antonie Stam ${ }^{3 \#}$ \\ ${ }^{1}$ Booking.com, Amsterdam, The Netherlands \\ 2Journalism Studies Department, School of Journalism, University of Missouri, Columbia, MO, USA \\ ${ }^{3}$ Management Department, Trulaske College of Business, University of Missouri, Columbia, MO, USA \\ Email: kate.stam@gmail.com, camerong@missouri.edu, " $\underline{\text { stama@missouri.edu }}$
}

Received 17 September 2014; revised 22 October 2014; accepted 15 November 2014

Copyright (C) 2014 by authors and Scientific Research Publishing Inc.

This work is licensed under the Creative Commons Attribution International License (CC BY). http://creativecommons.org/licenses/by/4.0/

(c) (i) Open Access

\section{Abstract}

Advertisers are keen on finding ways to leverage social network sites (SNS) such as Facebook, one of the premier SNS today, to improve their image, the perception of their products and sales revenue. Facebook facilitates social interaction online, and therefore develops a better understanding of the effect of impression management and social attractiveness on SNS. We focus on the impact of two prominent features of a Facebook profile, number of friends and number of photos that the user is tagged in, on user's perceived social attractiveness. Some SNS user profiles are perceived as more socially attractive than others. Presumably, a Facebook profile with a higher degree of social attractiveness will enhance the image of the organization, through positive association. In an experiment involving both graduate and undergraduate university students, almost all of them familiar with Facebook navigation, we find that, indeed, having more Facebook friends enhances social attractiveness, but likely only to a point. Having too many Facebook friends may have an adverse effect on social attractiveness. We also find that the number of photos that one is tagged in is an important determinant of social attractiveness, but only when considering alongside the number of friends. These findings suggest that we may have identified a conceptual SNS based advertising and PR design strategy with the potential to enhance perceived social attractiveness of the message. Through a carefully designed Facebook profile with the right balance between the number of friends and number of photos tagged, the profile's attractiveness may in turn inspire the customer to view the products or services offered in a more favorable light. Our results also suggest that other features of an SNS user profile-such as the profile picture, friend network and profile content-have the potential to affect social attractiveness. Interestingly and perhaps unexpectedly, in our study we also find that gender influences social attractiveness scores, with women perceived as more socially attractive when they have more friends, and men perceived as more socially attractive when they have fewer friends. One potential explanation for this gender-related finding is that a gender double standard may exist in the judgment of social attractiveness on Facebook. This issue suggests a need for further research on the gender issue. An ex-

\footnotetext{
*Parts of this work have previously been presented at the 2010 ICIME Conference in Cape Town, SA.

"Corresponding author.
} 
tension of our social attractiveness study to other SNS such as Twitter is welcome as well.

Keywords

Social Attractiveness, Social Network Sites, Facebook, New Technologies

\section{Introduction}

The explosive growth of the Internet has led to online social networking communities, allowing individuals to establish and maintain digital connections with each other. Different from a face-to-face networking environment, social network sites (SNS) are a new communication technology that gives users more or less complete control over the information that others can observe.

Similar to a face-to-face environment, certain SNS profiles are perceived as more socially attractive than others. Users may be able to manage profile information so as to manipulate their perceived social attractiveness. The purpose of this study is to develop a better understanding of how one can use effective impression management to design and build an attractive SNS profile. We will focus on Facebook, one of the most popular SNS worldwide with more than 1.23 billion active members in 2014 [1]. We apply impression management and social attractiveness theories to Facebook in an attempt to better comprehend how people perceive the social attractiveness of others, based on impressions of their profiles. An understanding of the cognitive processes involved may have relevant implications for the marketing and PR strategy of organizations in an SNS environment.

\section{Literature}

\subsection{Facebook}

Created in 2004, Facebook is a free-access SNS. The typical Facebook user spends about 20 minutes a day on the site and two-thirds of users log in at least once a day [2] [3], with as many as 90 percent of college students checking their Facebook accounts at least daily to see what is going on in the lives of their co-ed colleagues [4]. Previous Facebook-related research has covered several aspects of use, including identity, privacy, behavior, motivation, technology, content, and relationship development [5]-[7]. Most research on Facebook's social features covers the benefits of social networking sites, the benefits of Facebook "Friends", and the relationship between Facebook use and maintenance of social capital [8].

Another study found that Facebook profiles that divulge more personal information were linked to a larger network of friends [9]. The number of Facebook friends on a profile has been investigated [10] [11], but not in terms of social attractiveness. The role of photos tagged has not yet been analyzed in this context. The question whether personal Facebook features such as profile content, profile picture, and the number of tagged pictures can influence social attractiveness has not yet been studied in an SNS context. If social attractiveness in SNS can indeed be influenced, then this opens up great opportunities for organizations who wish to use Facebook to push their product or service to market.

\subsection{Facebook Friends}

Expanding the application of impression management to SNS, one study designed an experiment in which participants viewed mock Facebook profiles with various different numbers of friends [11]. The authors found that, the larger a user's online social network (measured by number of friends), the more positive impressions the user would generate- users with more Facebook friends were perceived as more popular, attractive and selfconfident. In other words, the number of friends in Facebook profiles triggers social judgments.

The results in [11] were challenged by [10], expressing doubt that the relationship between number of friends and positive impressions would persist for very high friend counts. Reference [12] reports that the mean count of Facebook friends is about 246. In an experiment where participants were shown Facebook profiles with between 102 and 902 friends, [10] found that for "small to medium" numbers of friends the relationship between number of friends and a user's social attractiveness is positive, whereas for "very high" numbers of friends, this rela- 
tionship is negative, suggesting a significant curvilinear effect for the relationship between number of friends on social attractiveness, with social attractiveness peaking for around 300 friends. Having substantially more than 300 Facebook friends ("a very high" number of friends) might be interpreted as evidence of disingenuous behavior rather than popularity.

The first research hypothesis that we test in our study seeks to confirm (or refute) the findings of [10] and [11] for "small" to "moderate" numbers of friends (up to around 300):

Hypothesis H1: As long as the number of Facebook friends is not "very high", having more friends is associated with a higher level of perceived social attractiveness.

\subsection{Interpersonal Attraction}

One focus of research on interpersonal attraction has been on the relationship between communication style, competence and perceived interpersonal attraction. Reference [13] found that social attraction is closely associated with responsiveness and that subordinates rate supervisors who are more available as more interpersonally attractive, while [14] determined that communication competence explains 17 percent of the variance in perceived social attractiveness.

Since the number of tagged photos is one measure of the extent of a Facebook user's social interaction, it is reasonable to suggest that it may also be a good predictor of social attractiveness. Moreover, it is plausible that there is an interaction effect between number of friends and number of tagged photos.

Reference [15] proposed an interpersonal judgment scale as a paradigm for interpersonal attraction. Another measure is the individual attraction scale developed by [16]. A third is the self-report Likert scale measures of interpersonal attraction designed by [17]. In our study, we selected the scale of [17], specifically its social attractiveness dimension, in part since this most frequently used and the above Facebook research used these measures as well [10].

Therefore, we test our second and third research hypotheses as follows:

Hypothesis H2: The higher the number of photos that a Facebook user is tagged in, the higher this user's perceived social attractiveness will be.

Hypothesis H3: The higher the number of tagged photos and the higher the number of friends (provided the number of friends is not "very high"), the higher a user's perceived social attractiveness will be.

Moreover, we suspect that gender of the Facebook profile owner will play a role in explaining social attractiveness:

Hypothesis H4: Profile gender affects the perceived social attractiveness associated with number of friends and number of tagged photos.

Gender and the number of tagged photos have not been considered in previous research on Facebook as potential determinants of social attractiveness, and testing $\mathrm{H} 2$ - $\mathrm{H} 4$ represents a novel contribution to the body of knowledge.

\section{Methods}

\subsection{Sample}

All participants in our experiment were subscribers to several listservs at a flagship U.S. public university, including the graduate student listserv of the School of Journalism, the doctoral student listserv of the School of Journalism, the undergraduate listserv of the School of Journalism and the undergraduate research listserv of the university. The total number of valid responses was 187, 59 males and 128 females, with a mean age of 22.5 (range 18 - 46, standard deviation $=4.2$ ). As students, the participants were likely to be comfortable with participating in academic surveys and experiments for research and course credit, and were therefore reasonably familiar with research procedures. The participants were also quite familiar with Facebook navigation, as only 5 of the 187 participants reported they did not have a Facebook account. Permission for this experiment was granted by the University of Missouri Institutional Review Board (IRB).

\subsection{Variables and Design}

The two manipulated stimuli (independent variables) were the number of friends (high = between 270 and 310; low = between 13 and 20) and the number of tagged photos (high = between 250 and 300; low = between 8 and 
20). Our hypotheses test whether these sociometric cues influence the dependent variable, social attractiveness. As the range of number of Facebook friends in our experiment is 13 - 310, it is not considered "very high" in terms of the scheme in [10] and consequently we did not test the curvilinear effect.

Social attractiveness was measured through the thirteen questions (items) summarized in Table 1, rated on a self-report Likert scale ranging from one to five, with $1=$ "Strongly Agree" and $5=$ "Strongly Disagree". The questions were reverse coded where necessary, so that for all items, 1 = "Strongly Agree" was a positive rating and 5 = "Strongly Disagree" was a negative rating. The items (questions), established by [17] and prior Facebook research [10], were then individually subjected to a principal-components factor analysis with Varimax rotation. A total of three factors with eigenvalues greater than 1.0 emerged from the factor analysis, each representing a different dimension of social attractiveness. Four items loaded on Factor 1, which we labeled Friendship, and appears to imply how likely participants were to make friends with the profile user; five items were loaded on Factor 2, Character, which appears to describe the profile user's personal attributes; and three items were loaded on Factor 3, Sameness, which seems to describe how "alike" participants believed they were with the profile's user. The factor loading is presented in Table 1. Testing the items contributing to each factor for reliability yielded $\alpha=0.780$ (Friendship), $\alpha=0.803$ (Character) and $\alpha=0.753$ (Sameness).

In summary, our study involves an experiment with a 2 (number of friends) $\times 2$ (number of tagged photos) $\times$ 2 (gender) repeated measures factorial design. A within-subjects design was used for the number of friends (high vs. low) and gender (male vs. female). A between-subjects design was used for the number of tagged photos (high vs. low).

\subsection{Profiles}

A total of eight mock Facebook profiles were created from four original profiles. The existing profiles of two males and two females were selected, with consent of the owners. To simulate an actual Facebook usage experience, the researchers took screenshots of the real Facebook profiles, while ensuring in the interest of privacy that all original names were altered and the profile holders' locations were disguised, so as to minimize the confounding variable of recognition. The number of tagged photos and the number of friends for each profile were manipulated in Photoshop. We deleted extra applications and text, such as video and negative wall posts, to prevent distraction from the stimuli. Each mock profile was saved as a PDF file and uploaded to a Googlehosted Web site. SurveyMonkey linked to each PDF file as appropriate.

Several pre-tests were conducted to assure that the questions in the questionnaire were clear and easy to answer. In the pre-tests it took less than 10 minutes on average for participants to complete the experiment.

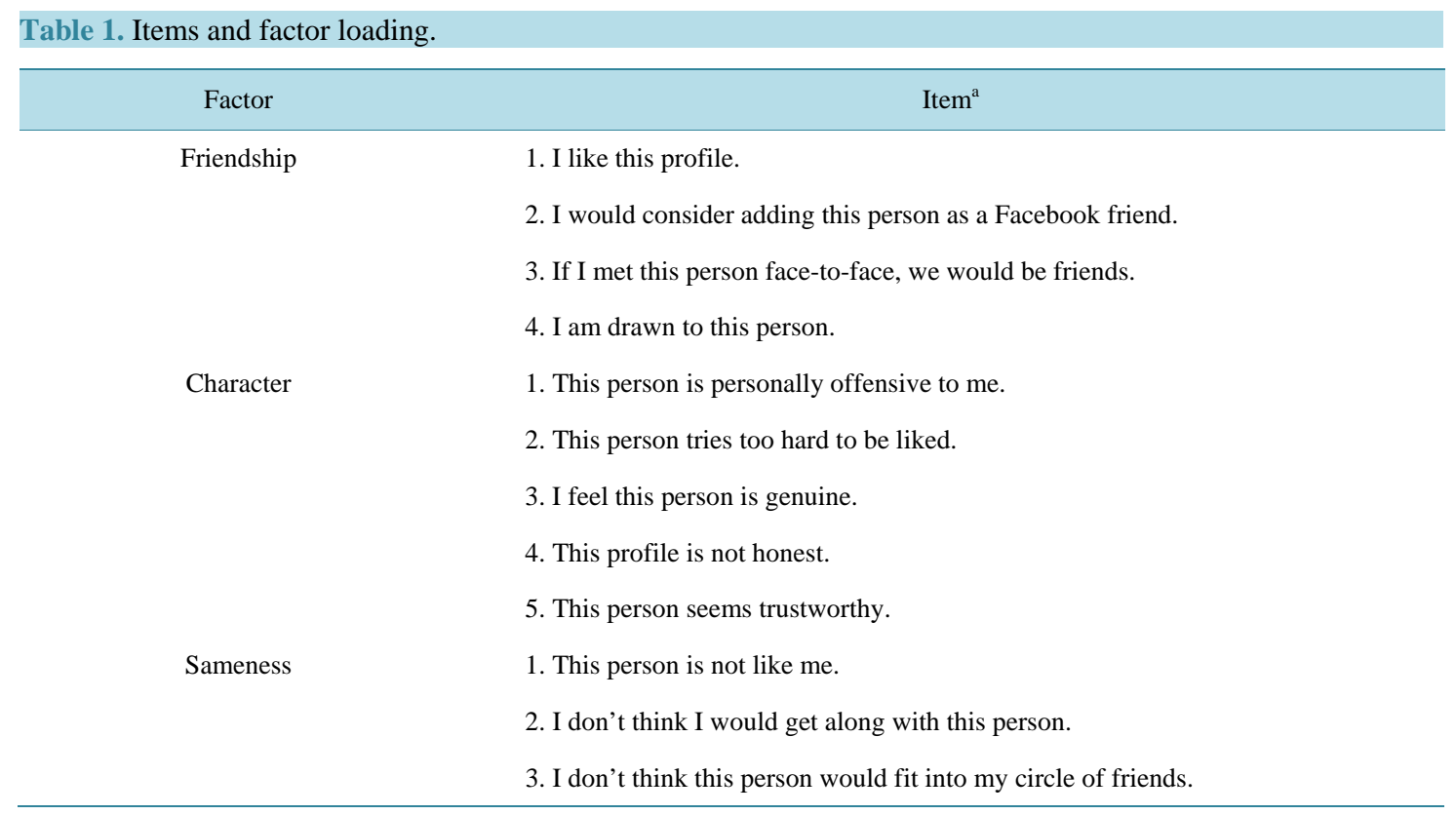

a'One item ("This person is popular”) was dropped because it did not load to any factor. 


\subsection{Procedure}

Each participant was sent an e-mail with a link to the SurveyMonkey questionnaire. The e-mail included a short description of the study. When participants clicked the link, they were taken to SurveyMonkey and were given a more detailed description of the study.

Participants were assigned to two groups based on the first letter of their last names and presented with four different profiles. Group 1 constituted participants whose last names began with A - M, and they viewed the following four profiles: high number of tagged photos with high number of friends (one male, one female profile) and high number of tagged photos with low number of friends (one male, one female profile). Group 2 constituted participants whose last names began with $\mathrm{N}-\mathrm{Z}$, and they viewed the following four profiles: low number of tagged photos with high number of friends (one male, one female profile) and low number of tagged photos with low number of friends (one male, one female profile).

Profiles opened in a separate window. Some participants were instructed to download the profile, but depending on computer type, this was not always necessary. Participants were provided with a link to each profile, one at the time, and evaluated the 13 questions about social attractiveness in Table 1 for each profile, in randomized order. Note that Profiles 1 to 4 were exactly the same for both Group 1 and Group 2, except for the stimuli (number of tagged photos and number of friends). After completing the questionnaire, participants provided demographics information and answered questions concerning their own personal Facebook use.

\section{Results}

Three 2 (number of friends) $\times 2$ (number of tagged photos) mixed-design ANOVAs were used to examine the effect of number of friends on Friendship, Character and Sameness. The results in Table 2 suggest significant main effects for the number of friends on Friendship $(F(1,185)=7.000, p=0.009)$ and for the number of friends on Character $(F(1,185)=7.873, p=0.006)$. The main effect for the number of friends on Sameness, however, is not significant $(F(1,185)=0.237, \mathrm{p}=0.627)$. Hence, with two out of three main effects significant, $\mathrm{H} 1$ is partially supported: the higher the number of friends a Facebook profile has, the higher the profile's perceived social attractiveness will be.

Three 2 (number of friends) $\times 2$ (number of tagged photos) mixed-design ANOVAs were used to examine the effect of the number of tagged photos on Friendship, Character and Sameness. Table 2 suggests that none of the main effects, for the number of tagged photos on Friendship $(\mathrm{F}(1,185)=0.048, \mathrm{p}=0.827)$, on Character $(\mathrm{F}(1,185)=0.391, \mathrm{p}=0.532)$, and on Sameness $(\mathrm{F}(1,185)=0.142, \mathrm{p}=0.701)$ are significant, so that $\mathrm{H} 2$ is clearly not supported: Higher numbers of photos a Facebook profile is tagged in are NOT associated with higher levels of social attractiveness.

Three 2 (number of friends) $\times 2$ (number of tagged photos) mixed-design ANOVAs were used to examine the effect of the number of tagged photos and the number of friends on Friendship, Character and Sameness. The results in Table 3 and illustrated in Figure 1 show that the joint event of high (low) number of tagged photos and high (low) number of friends exhibits a significant positive interaction with Sameness $(F(1,185)=3.797$, $p$ $=0.053$ ), i.e., high (low) number of friends and high (low) number of tagged photos jointly tend to be associated with stronger perceptions of Sameness. The other interaction effects of the joint event of number of friends and tagged photos with Friendship $(\mathrm{F}(1,185)=2.927, \mathrm{p}=0.89)$ and Character $(\mathrm{F}(1,185)=0.537, \mathrm{p}=0.465)$ were not statistically significant. Thus, H3 is partly supported: the higher a profile's number of tagged photos and the higher a profile's number of friends, the higher the social attractiveness rating will be.

Table 2. Mean social attractiveness ratings and F-values for high vs. low number of friends and high vs. low number of tagged photos ( 1 = most attractive, 5 = least attractive).

\begin{tabular}{ccccccc}
\hline Factor & $\begin{array}{c}\text { High \# } \\
\text { friends } \\
\text { mean (SD) }\end{array}$ & $\begin{array}{c}\text { Low } \# \\
\text { friends } \\
\text { mean (SD) }\end{array}$ & F-value & $\begin{array}{c}\text { High \# } \\
\text { photos } \\
\text { mean (SD) }\end{array}$ & $\begin{array}{c}\text { Low \# } \\
\text { photos } \\
\text { mean (SD) }\end{array}$ & F-value \\
\hline Friendship & $3.2(7.00)$ & $3.3(0.68)$ & $7.000^{\mathrm{b}}$ & $3.2(0.71)$ & $3.2(0.66)$ & 0.048 \\
Character & $2.4(0.60)$ & $3.0(0.61)$ & $7.873^{\mathrm{b}}$ & $2.4(0.62)$ & $2.5(0.59)$ & 0.391 \\
Sameness & $2.9(0.76)$ & $2.9(0.72)$ & 0.237 & $2.9(0.74)$ & $2.9(0.74)$ & 0.142 \\
\hline
\end{tabular}

${ }^{\mathrm{b}} \mathrm{p}<0.05$. 


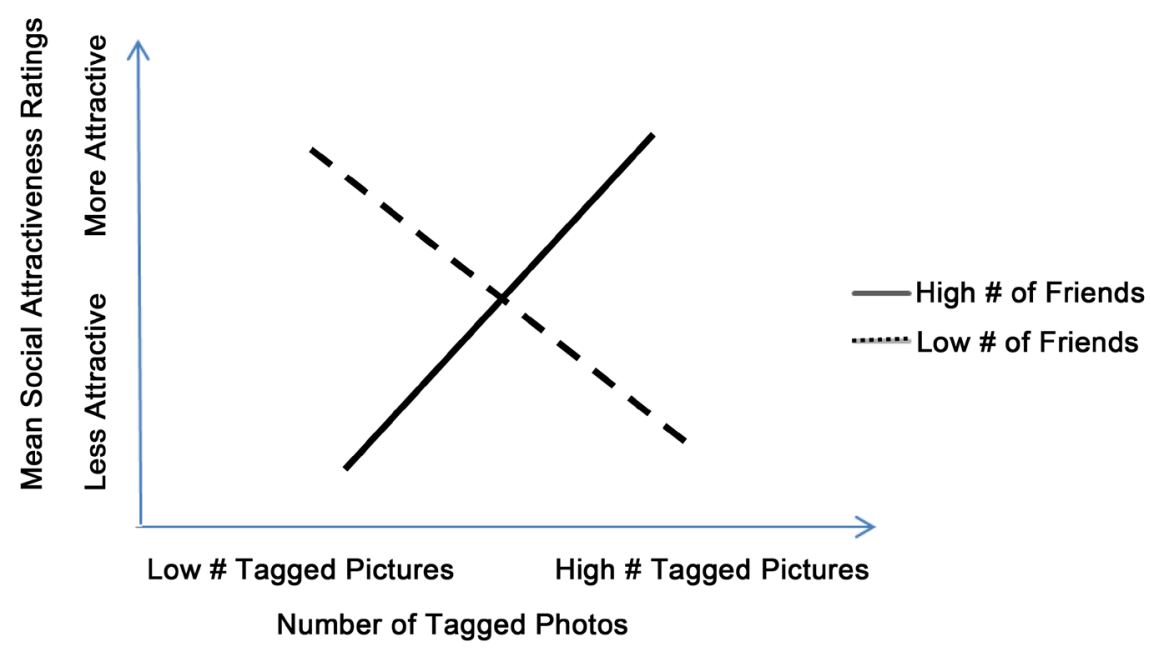

Figure 1. The interaction between number of friends and number of tagged pictures.

Table 3. Mean social attractiveness ratings and F-values for number of friends and number of tagged photos interaction ( 1 = most attractive, 5 = least attractive).

\begin{tabular}{|c|c|c|c|c|c|}
\hline $\begin{array}{c}\text { Factor } \\
\text { high \# photos } \\
\text { mean (SD) }\end{array}$ & $\begin{array}{c}\text { High \# friends, } \\
\text { low \# photos } \\
\text { mean (SD) }\end{array}$ & $\begin{array}{l}\text { High \# friends, } \\
\text { high \# photos } \\
\text { mean (SD) }\end{array}$ & $\begin{array}{c}\text { Low \# friends, } \\
\text { low \# photos } \\
\text { mean (SD) }\end{array}$ & $\begin{array}{l}\text { Low \# friends, } \\
\text { high \# photos }\end{array}$ & F-value \\
\hline Friendship & $3.1(0.72)$ & $3.2(0.66)$ & $3.2(0.69)$ & $3.2(0.67)$ & 0.537 \\
\hline Character & $2.4(0.61)$ & $2.4(0.60)$ & $2.5(0.62)$ & 2.5 (0.59) & 2.927 \\
\hline Sameness & $2.8(0.73)$ & $2.9(0.79)$ & $2.9(0.74)$ & $2.9(0.68)$ & $3.797^{\mathrm{a}}$ \\
\hline
\end{tabular}

${ }^{\mathrm{a}} \mathrm{p}<0.10$.

The results pertaining to the gender hypothesis H4 proved very interesting. As shown in Table 4, significant main effects were observed for profile gender on Friendship $(F(1,185)=8.230, p=0.005)$ and Sameness $(\mathrm{F}(1,185)=5.440, \mathrm{p}=0.021)$, with male profiles rated more positively; no significant interaction was found for Character $(F(1,185)=1.178, p=0.279)$. Table 5 indicates that gender also interacted with number of friends, both for Character $(F(1,185)=28.082$, $p<0.001)$ and Sameness $(F(1,185)=20.469, p<0.001)$; a marginal result was found for Friendship $(\mathrm{F}(1,185)=2.917, \mathrm{p}=0.089)$. This finding is depicted graphically in Figure 2 . Thus, male profiles with lower numbers of friends were rated as more attractive, whereas female profiles with higher numbers of friends were rated as more attractive.

\section{Discussion}

\subsection{Summary}

The findings in our study indicate several significant sociometric cues on Facebook profiles. First, higher numbers of friends tend to enhance the Friendship and Character dimensions of social attractiveness, partly supporting H1. Second, the number of tagged photos did not generate a significant influence on social attractiveness, so that H2 was not supported. However, when considered alongside number of friends, the number of tagged photos appears to impact social attractiveness as measured by Sameness, but not along the other two dimensions (Friendship and Character). Social attractiveness as measured by Sameness appears high when both numbers are high, or when both numbers are low. If one number is high and the other is low, however, social attractiveness as measured by Sameness is less. Therefore, H3 is partly supported.

Interestingly, profile gender exerts a very significant $(\mathrm{p}<0.01)$ influence on social attractiveness. Profile gender directly influences Friendship and Sameness, while the interaction between profile gender and number of friends affects social attractiveness along both the Character and Sameness dimensions. 


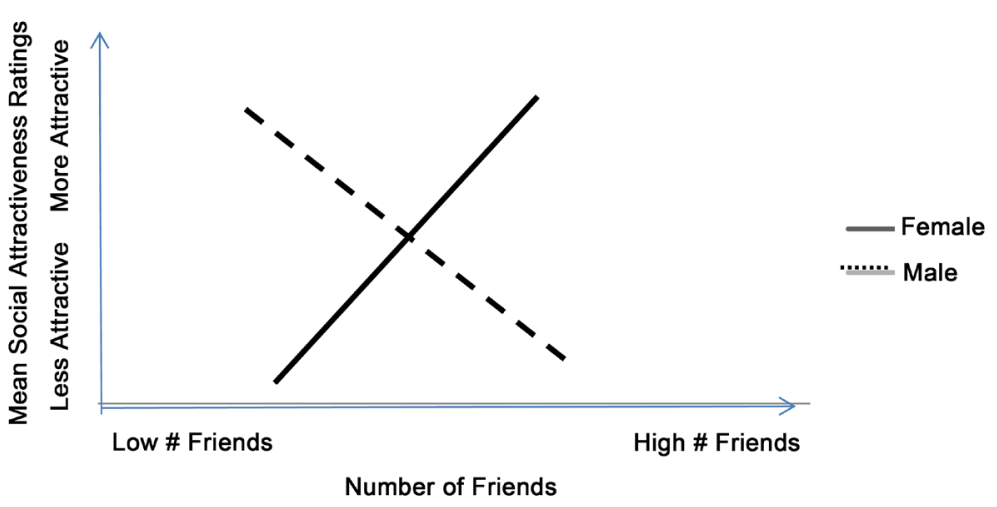

Figure 2. The interaction between profile gender and number of friends.

Table 4. Mean social attractiveness ratings and F-values based on profile gender $(1=$ most attractive, $5=$ least attractive).

\begin{tabular}{cccc}
\hline Factor & Male profiles mean (SD) & Female profiles mean (SD) & F-value \\
\hline Friendship & $3.2(0.70)$ & $3.3(0.68)$ & $8.230^{\mathrm{b}}$ \\
Character & $2.5(0.70)$ & $2.4(0.60)$ & 1.178 \\
Sameness & $2.8(0.75)$ & $2.9(0.72)$ & $5.440^{\mathrm{a}}$ \\
\hline
\end{tabular}

${ }^{\mathrm{a}} \mathrm{p}<0.10 ;{ }^{\mathrm{b}} \mathrm{p}<0.05$.

Table 5. Mean social attractiveness ratings and F-values for profile gender and number of friends interaction $(1=$ most attractive, 5 = least attractive).

\begin{tabular}{cccccc}
\hline Factor & $\begin{array}{c}\text { Male profiles, } \\
\text { high \# friends }\end{array}$ & $\begin{array}{c}\text { Male profiles, } \\
\text { low \# friends }\end{array}$ & $\begin{array}{c}\text { Female profiles, } \\
\text { high \# friends }\end{array}$ & $\begin{array}{c}\text { Female profiles, } \\
\text { low \# friends }\end{array}$ & F-value \\
\hline Friendship & $3.1(0.72)$ & $3.2(0.68)$ & $3.2(0.67)$ & $3.4(0.067)$ & $2.917^{\mathrm{a}}$ \\
Character & $2.5(0.65)$ & $2.4(0.58)$ & $2.3(0.53)$ & $2.6(0.63)$ & $28.082^{\mathrm{c}}$ \\
Sameness & $2.9(0.78)$ & $2.8(0.72)$ & $2.8(0.73)$ & $3.1(0.69)$ & $20.469^{\mathrm{c}}$ \\
\hline
\end{tabular}

${ }^{\mathrm{a}} \mathrm{p}<0.10 ;{ }^{\mathrm{c}} \mathrm{p}<0.01$.

\subsection{Interpretations, Implications and Alternative Explanations}

According to our study, Facebook profiles are perceived as more popular and genuine when the number of Facebook friends is high. People appear drawn to users with a high number of friends, and are more likely to want to make a social connection as a Facebook friend or face-to-face friend. Although the number of photos tagged in a profile is not significant by itself, it does appear to be an important parameter of social attractiveness when considered along with the number of friends. The interaction effect between the number of friends and number of tagged photos suggests that people tend to rate users with both high (low) numbers of friends and high (low) numbers of tagged photos as more socially attractive. However, users who have a high (low) number of friends and a low (high) number of tagged photos are perceived as less socially attractive.

The finding suggests that the two sociometric cues, number of friends and number of tagged photos, are expected to be consistent-in order to be socially attractive, a user should have either a high number of friends and a high number of photos, or a low number of friends and a low number of photos. Inconsistencies make observers feel as though they have less in common with the user, resulting in a lower rating of social attractiveness. Therefore, people not only consider how many friends a profile has, but they also consult the general consistency of sociometric cues.

The number of friends and tagged photos influenced social attractiveness for men and women differently. Female profiles with a high number of friends were notably more socially attractive than those with low number of friends. In contrast, male users had the opposite pattern. Men with a lower number of friends were slightly 
more socially attractive than those with many friends. This phenomenon suggests that people set different standards concerning sociometric cues for men and women on Facebook, at least for social attractiveness. This implication is consistent with [18], a study of the double standard theory, which claims that people tend to judge women with stricter standards than men. Reference [12] also suggested that sexual double standards lead to differences in the evaluation of men and women. While men may still receive confirmation when exhibiting negative behaviors, women are belittled for similar behaviors. Accordingly, we find evidence of a gender double standard in the judgment of social attractiveness on Facebook.

\subsection{Limitations}

A major limitation of this study is that it examines only the upward slope of the (possibly) quadratic relationship between Facebook users' social attractiveness and number of friends. Patterns of social attractiveness might differ when also applied to the downward slope of the quadratic relationship, when a user's number of friends is "very high". Another limitation of the study is the order effect. Although the social attractiveness questions were presented in randomized order, the order of presentation of Facebook profiles was not.

\subsection{Suggestions for Future Research}

In addition to studying how the curvilinear relationship between social attractiveness and number of friends might affect other sociometric cues on Facebook, future research should investigate in more details how gender impacts social attractiveness. For example, one might investigate how profile gender and the observer's gender might interact to impact social attractiveness ratings; or whether gender double standard persists in other, nonsociometric aspects of social attractiveness. Answering these questions would provide more knowledge about impression management on Facebook profiles, and how Facebook users are judged by others.

As SNS continue to grow in importance, it would also be valuable to investigate social attractiveness on other types of SNS sites, such as Twitter. For example, is network size as important on Twitter as it seems to be on Facebook? Are males and females judged differently on Twitter, as evidence suggests they are on Facebook?

Finally, it appears to the authors that the issue of social attractiveness on SNS may have deep implications for advertising, marketing and PR, in which an organization may have some control over its perceived image through the design of their Facebook profile.

\section{References}

[1] The Guardian (2014) Facebook: 10 Years of Social Networking, in Number. February 4, 2014. http://www.theguardian.com/technology/2014/feb/04/facebook-10-years-mark-zuckerberg

[2] Cassidy, J. (2006) Me Media: How Hanging out on the Internet Became Big Business. The New Yorker, May 15, 50-59.

[3] May, M. and Kwong, K.H. (2007) YHOO: Yahoo! May Regret Not Paying up for Facebook. http://www.needhamco.com/Research/Documents/CPY25924.pdf

[4] Clark, N., Boyer, L. and Lee, S. (2007) A Place of Their Own: An Exploratory Study of College Students' Uses of Facebook. Proceedings of the Annual Meeting of the International Communication Association, San Francisco. http://citation.allacademic.com/meta/p172779_index.html

[5] Boyd, D. (2007) Social Network Sites: Public, Private, or What? Knowledge Tree. http://kt.flexiblelearning.net.au/tkt2007/?page_id=28

[6] Dwyer, C., Hiltz, S. and Passerini, K. (2007) Trust and Privacy Concern within Social Networking Sites: A Comparison of Facebook and MySpace. Proceedings of the Thirteenth Americas Conference on Information Systems, Keystone, Paper 339. http://aisel.aisnet.org/amcis2007/339/

[7] Felt, A., Hooimeijer, P., Evans, D. and Weimer, W. (2008) Talking to Strangers without Taking Their Candy: Isolating Proxied Content. Proceedings of the 1st Workshop on Social Network Systems, Glasgow, 25-30. http://dx.doi.org/10.1145/1435497.1435502

[8] Ellison, N., Steinfield, C. and Lampe, C. (2007) The Benefits of Facebook "Friends", Social Capital and College Students’ Use of Online Social Network Sites. Journal of Computer-Mediated Communication, 12, 1143-1168. http://dx.doi.org/10.1111/j.1083-6101.2007.00367.x

[9] Lampe, C.A., Ellison, N. and Steinfield, C. (2007) A Familiar Face(book): Profile Elements as Signals in an Online Social Network. In: Proceedings of the SIGCHI Conference on Human Factors in Computing Systems, ACM Press, 
San Jose, 435-444. http://dx.doi.org/10.1145/1240624.1240695

[10] Tong, S., Van Der Heide, B., Langwell, L. and Walther, J. (2008) Too Much of a Good Thing? The Relationship between Number of Friends and Interpersonal Impressions on Facebook. Journal of Computer-Mediated Communication, 13, 532-549. http://dx.doi.org/10.1111/j.1083-6101.2008.00409.x

[11] Kleck, C., Reese, C., Ziegerer-Behnken, D. and Sundar, S. (2007) The Company You Keep and the Image You Project: Putting Your Best Face Forward in Online Social Networks. Proceedings of the 57th Annual Conference of the International Communication Association, San Francisco, 24-28 May 2007.

[12] Walther, J.B., Van Der Heide, B., Kim, S.Y., Westerman, D. and Tong, S.T. (2008) The Role of Friends? Appearance and Behavior on Evaluations of Individuals on Facebook: Are We Known by the Company We Keep? Human Communication Research, 34, 28-49. http://dx.doi.org/10.1111/j.1468-2958.2007.00312.x

[13] McCroskey, J.C. and Richmond, V.P. (2000) Applying Reciprocity and Accommodation Theories to Supervisor/Subordinate Communication. Journal of Applied Communication Research, 28, 278-289. http://dx.doi.org/10.1080/00909880009365575

[14] Duran, R. and Kelly, L. (1988) The Influence of Communicative Competence on Perceived Task, Social, and Physical Attraction. Communication Quarterly, 36, 41-49. http://dx.doi.org/10.1080/01463378809369706

[15] Byrne, D. (1971) The Attraction Paradigm. Academic Press, New York.

[16] Clatterbuck, G. (1979) Attributional Confidence and Uncertainty in Initial Interactions. Human Communication Research, 5, 147-157. http://dx.doi.org/10.1111/j.1468-2958.1979.tb00630.x

[17] McCroskey, J.C. and McCain, T.A. (1974) The Measurement of Interpersonal Attraction. Speech Monographs, 41, 261-266. http://dx.doi.org/10.1080/03637757409375845

[18] Foschi, M. (1996) Double Standards in the Evaluation of Men and Women. Social Psychology Quarterly, 59, $237-254$. http://dx.doi.org/10.2307/2787021 
Scientific Research Publishing (SCIRP) is one of the largest Open Access journal publishers. It is currently publishing more than 200 open access, online, peer-reviewed journals covering a wide range of academic disciplines. SCIRP serves the worldwide academic communities and contributes to the progress and application of science with its publication.

Other selected journals from SCIRP are listed as below. Submit your manuscript to us via either submit@scirp.org or Online Submission Portal.
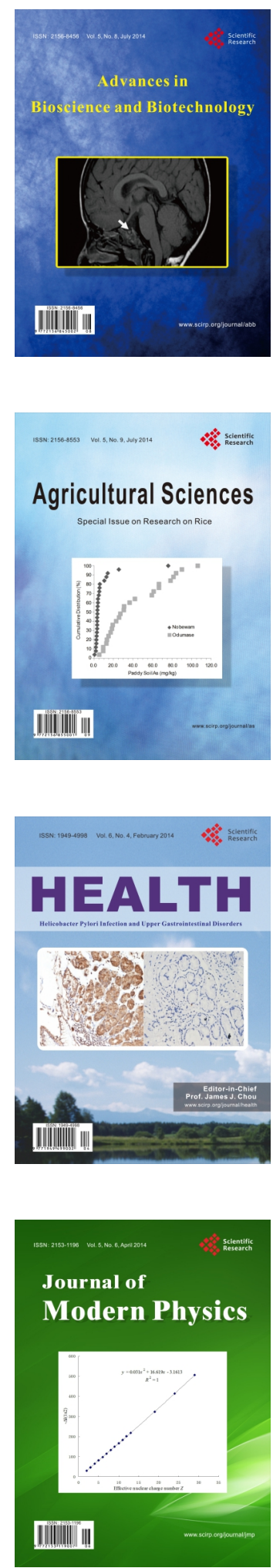
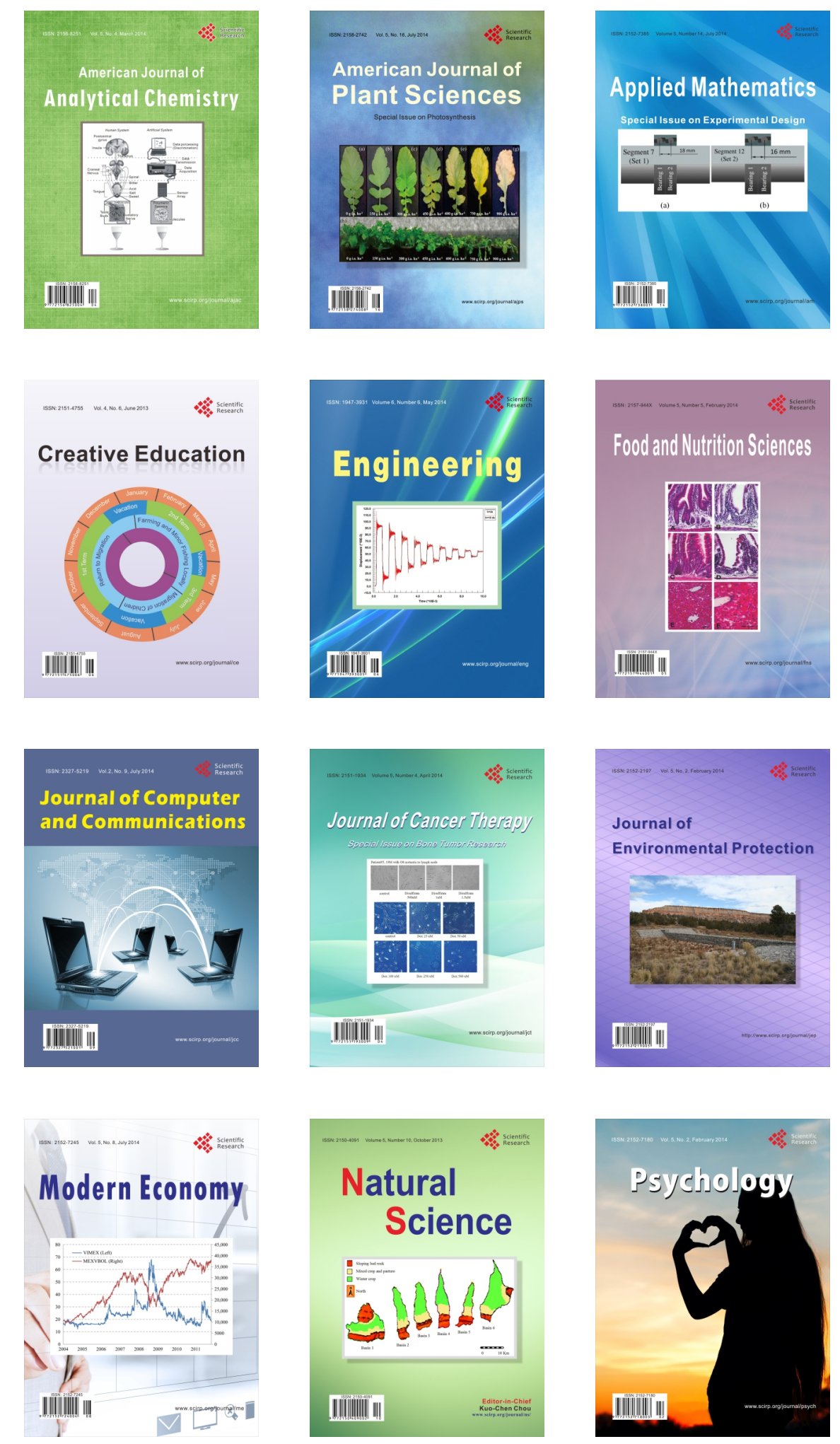